\title{
Pengelolaan Penyediaan Parkir sebagai Upaya Mendukung Pariwisata Berkelanjutan di Taman Wisata Alam Kawah Ijen, Kabupaten Banyuwangi
}

\author{
Achmad Fauzan Iscahyono ${ }^{1)}$ \\ ${ }^{(1)}$ Staf Pengajar, Program Studi Perencanaan Wilayah dan Kota, Institut Teknologi Nasional Bandung. (fauzancahyo@gmail.com)
}

\begin{abstract}
Abstrak
Di Kabupaten Banyuwangi, terdapat objek wisata Taman Wisata Alam (TWA) Kawah ljen di mana jumlah wisatawan yang mengunjungi lokasi tersebut selalu mengalami peningkatan setiap tahunnya sehingga dikhawatirkan akan melebihi daya dukung wisata alam tersebut. Oleh karena itu, diperlukan strategi berupa pengelolaan pembatasan penyediaan parkir di TWA Kawah ljen untuk menjaga kelestasian kawasan konservasi alam tersebut agar jumlah wisatawan yang mengunjungi destinasi wisata tersebut tidak melebihi daya dukung lahan wisatanya. Penelitian ini bertujuan untuk menganalisis penyediaan parkir sebagai upaya mendukung pariwisata keberlanjutan di TWA Kawah ljen melalui melakukan perhitungan kebutuhan penyediaan parkir dan yang kemudian dibandingkan dengan hasil perhitungan batasan daya dukung fisik TWA Kawah ljen diharapkan mampu mengetahui batasan jumlah wisatawan yang dapat ditampung di TWA Kawah ljen.
\end{abstract}

Kata-kunci : daya dukung fisik, parkir, wisata,

\begin{abstract}
In Banyuwangi Regency, there is a tourist attraction ljen Crater Nature Tourism Park (TWA) where the number of tourists who visiting ljen Crater Nature Tourism Park (TWA) always increases every year so it is feared that it will exceed the carrying capacity of these natural attractions. Therefore, a strategy is needed to manage parking provision in ljen Crater Nature Tourism Park (TWA) so it can conserv the nature conservation area so that the number of tourists visiting the tourist destination does not exceed the carrying capacity of the tourism. This study aims to analyze the provision of parking as an effort to support sustainable tourism in ljen Crater Nature Tourism Park (TWA) through calculating the needs of parking lots and then compared with the results of calculating the physical carrying capacity limitation of ljen Crater Nature Tourism Park (TWA) is expected to be able to know the limits of the number of tourists that can be accommodated in ljen Crater Nature Tourism Park (TWA).
\end{abstract}

Keywords : tourism, physical carrying capacity, parking

\section{Pengantar}

Pembangunan pariwisata alam yang berkelanjutan sudah menjadi pertimbangan dalam pengelolaan sumber daya alam yaitu bahwa kebutuhan ekonomi, sosial, dan estetika dapat dipenuhi sambil memelihara integritas budaya, proses esensial ekologi, keanekaragaman biologi, dan sistem penyangga kehidupan (Steck, 1999). Konsep pariwisata yang berkelanjutan tersebut merupakan penurunan dari konsep sustainable development. Komisi Dunia untuk lingkungan dan Pembangunan (World Commission on
Environment and Development - WECD) mendefinisikan sustainable development atau pembangunan berkelanjutan sebagai pembangunan yang dapat memenuhi kebutuhan sekarang tanpa mengorbankan kemampuan generasi yang akan datang untuk memenuhi kebutuhannya (Permana, 2016). Menurut Azis (2010), yang dibutuhkan dalam pembangunan berkelanjutan adalah tiga hal yang tumbuh bersama-sama, yaitu aspek lingkungan, sosial, dan ekonomi yang saling berinteraksi satu dengan lainnya. Kemudian, konsep pembangunan berkelanjutan tersebut diadopsi ke dalam konsep pembangunan 
pariwisata berkelanjutan (Suryadana, 2013). Menurut Tim Kementrian Pariwisata (2017), pariwisata berkelanjutan secara sederhana dapat didefinisikan sebagai pariwisata yang memperhitungkan penuh dampak ekonomi, sosial dan lingkungan saat ini dan masa depan, memenuhi kebutuhan pengunjung, industri, lingkungan dan masyarakat setempat. Prinsipprinsip keberlanjutan mengacu pada aspek lingkungan, ekonomi, dan sosial-budaya dari suatu destinasi wisata.

Daya dukung lingkungan obyek wisata alam adalah kemampuan obyek wisata alam untuk dapat menampung jumlah wisatawan pada luas dan satuan waktu tertentu (Soemarwoto, 2004). World Tourism Organisation (WTO) memberi pengertian daya dukung wisata sebagai jumlah maksimum orang yang boleh mengunjungi satu tempat wisata pada saat bersamaan tanpa menyebabkan kerusakan lingkungan fisik, ekonomi, dan sosial budaya dan penurunan kualitas yang merugikan bagi kepuasan wisatawan (Livina, 2009). Pada dasarnya, ada dua aspek dalam pemanfaatan wisata yang secara integral berkaitan dengan daya dukung yaitu melindungi sumber daya dan kualitas pengalaman berwisata (Sayan dan Atik, 2011).

Di Kabupaten Banyuwangi, terdapat Taman Wisata Alam (TWA) Kawah ljen yang merupakan objek wisata andalan di WPP (Wilayah Pengembangan Pariwisata) I sesuai arahan rencana kawasan strategis berdasarkan Rencana Tata Ruang Wilayah (RTRW) Kabupaten Banyuwangi. Secara administratif, Kawah ljen terletak di Desa Tamansari, Kecamatan Licin yang dapat diakses dari Kabupaten Bondowoso maupun pusat kota Kabupaten Banyuwangi. Pada perkembangan selanjutnya, tanggal 10 Desember 1981 melalui Surat Keputusan Menteri Pertanian No.1017/KPTSII/Um/12/1981, menetapkan sebagian dari kawasan Cagar Alam Kawah ljen seluas 92 hektar menjadi Taman Wisata Alam Kawah ljen, sedangkan sisanya seluas 2.468 hektar tetap sebagai cagar alam. Pengelolaan Taman Wisata Alam Kawah ljen berada di bawah Balai Besar Konservasi Sumber Daya Alam (BKSDA) Jawa Timur.

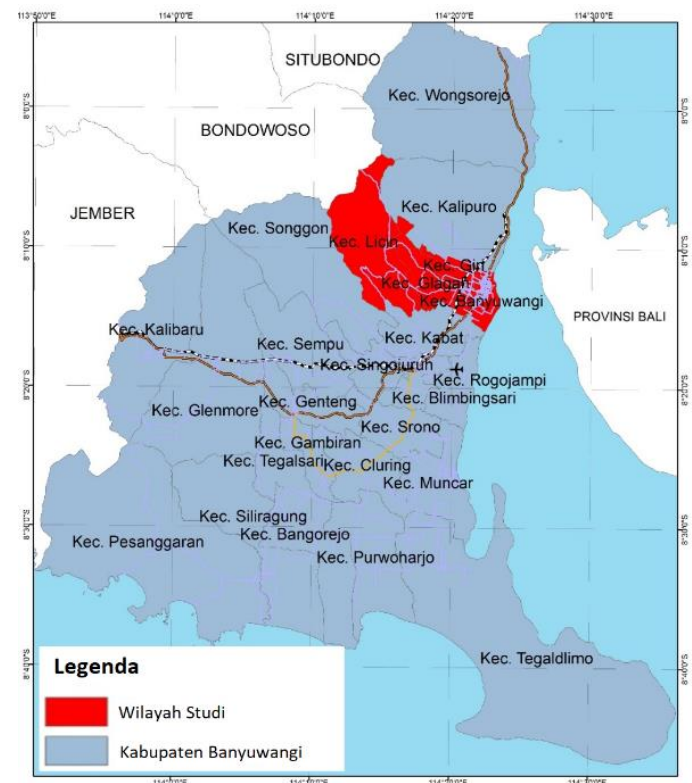

Gambar 1. Peta Wilayah Studi

(Sumber: Bappeda Kabupaten Banyuwangi)

Pada umumnya, pariwisata di kawasan konservasi terdiri dari dua jenis yaitu dalam skala kecil atau minat khusus (ekowisata) yang mungkin akan memberikan dampak yang kecil bagi ekosistem dan dalam skala besar/wisata massal yang melibatkan banyak komponen dan akan memberi dampak besar bagi ekosistem (McCool dan Moisey, 2008). Agar tidak memberi dampak besar bagi ekosistem, Taman Wisata Alam (TWA) Kawah Ijen diharapkan menjadi destinasi pariwisata dengan jenis skala kecil atau minat khusus. Namun berdasarkan data yang berasal dari Dinas Kebudayaan dan Pariwisata Kabupaten Banyuwangi, jumlah wisatawan yang mengunjungi Taman Wisata Alam (TWA) Kawah ljen selalu mengalami peningkatan setiap tahunnya di mana terdapat 100.768 pengunjung pada tahun 2014, 171.900 pengunjung pada tahun 2015, dan 202.919 pada tahun 2016. Jika jumlah pengunjung tersebut terus mengalami peningkatan setiap tahunnya, dikhawatirkan akan melebihi daya dukung wisata alam tersebut. Oleh karena itu, diperlukan strategi untuk menjaga kelestasian kawasan konservasi alam tersebut agar jumlah wisatawan yang mengunjungi destinasi wisata tersebut tidak melebihi daya dukung wisata.

Terdapat beberapa alternatif strategi yang dapat diupayakan agar jumlah wisatawan yang mengunjungi destinasi wisata tersebut tidak 
melebihi daya dukung wisata untuk menjaga kelestarian kawasan konservasi alam tersebut. Salah satu strategi yang telah dicanangkan oleh Pemerintah Kabupaten Banyuwangi yang dinilai mampu mendukung menjaga kelestarian di Taman Wisata Alam (TWA) Kawah ljen adalah dengan menyediakan angkutan khusus untuk mengakomodasi kebutuhan transportasi menuju lokasi-lokasi wisata yang tersebar di seluruh Kabupaten Banyuwangi secara gratis di mana angkutan wisata gratis ini diluncurkan pada bulan Juli tahun 2017 dan memiliki 3 unit armada yaitu 1 unit bus, 1 unit ELF dan 1 unit trooper. Strategi lainnya yang memungkinkan untuk mendukung pembatasan jumlah wisatawan adalah dengan melakukan pengelolaan penyediaan parkir di Taman Wisata Alam (TWA) Kawah ljen. Strategi ini diharapkan dapat pula berfungsi dalam mengelola pembatasan jenis kendaraan yang boleh memasuki area parkir di mana pengelolaan kendaraan-kendaraan tersebut dapat berdampak pada pembatasan pengunjung yang juga sebagai penumpang dari kendaraan-kendaraan tersebut.

Berdasarkan penjelasan di atas, penelitian ini bertujuan untuk menganalisis penyediaan parkir sebagai upaya mendukung pariwisata keberlanjutan di Taman Wisata Alam (TWA) Kawah Ijen Kabupaten Banyuwangi. Penyediaan parkir tersebut berdasarkan hasil perhitungan daya dukung wisata Taman Wisata Alam (TWA) Kawah ljen. Hasil penelitian ini diharapkan dapat menjadi saran atau masukan sebagai salah satu upaya melestarikan kelestarian lingkungan Taman Wisata Alam (TWA) Kawah ljen, terutama Balai Besar Konservasi Sumber Daya Alam (BKSDA) Jawa Timur bersama Pemerintah Daerah Kabupaten Banyuwangi.

\section{Tinjauan Literatur}

Berdasarkan Keputusan Direktur Jenderal Perhubungan Darat Nomor: 272/HK.105/DRJD/96 tentang Pedoman Teknis Penyelenggaraan Fasilitas Parkir, fasilitas parkir merupakan lokasi yang ditentukan sebagai tempat pemberhentian kendaraan yang tidak bersifat sementara untuk melakukan kegiatan pada suatu kurun waktu. Jumlah penyediaan parkir disesuaikan sedemikian rupa sehingga dapat memenuhi permintaan parkir termasuk pada periode puncak kunjungan untuk masing-masing kegiatan (Lisnawati, 2014). Namun, kondisi tersebut tidak selalu terjadi dikarenakan adanya keterbatasan ketersediaan lahan, faktor biaya, atau adanya upaya pengendalian pergerakan kendaraan (Young, 2001).

Perhitungan kebutuhan ruang parkir dapat merujuk pada penentuan Satuan Ruang Parkir (SRP) berdasarkan Keputusan Direktur Jenderal Perhubungan Darat Nomor: 272/HK.105/DRJD/96 tentang Pedoman Teknis Penyelenggaraan Fasilitas Parkir. Besaran satuan ruang parkir untuk tiap jenis kendaraan adalah sebagai berikut.

Tabel 1.1 Penentuan Satuan Ruang Parkir (SRP)

\begin{tabular}{lll}
\hline No & Jenis Kendaraan & $\begin{array}{l}\text { Satuan Ruang } \\
\text { Parkir }\left(\mathrm{m}^{2}\right)\end{array}$ \\
\hline 1 & $\begin{array}{l}\text { Mobil Penumpang } \\
\text { untuk golongan I }\end{array}$ & $2,30 \times 5,00$ \\
\cline { 2 - 3 } & $\begin{array}{l}\text { Mobil Penumpang } \\
\text { untuk golongan II }\end{array}$ & $2,5 \times 5,00$ \\
\cline { 2 - 3 } & $\begin{array}{l}\text { Mobil Penumpang } \\
\text { untuk golongan III }\end{array}$ & $3,00 \times 5,00$ \\
\hline 2 & Bus / Truk & $3,4 \times 12,50$ \\
\hline 3 & Sepeda Motor & $0,75 \times 2,00$ \\
\hline \multirow{2}{*}{ Sumber: Pedoman Teknis } & Penyelenggaraan \\
\multicolumn{3}{l}{ Fasilitas Parkir }
\end{tabular}

Sedangkan bagian berikut akan memaparkan mengenai pendetailan satuan ruang parkir untuk masing-masing jenis kendaraan. Gambar di bawah ini akan memaparkan mengenai satuan ruang parkir untuk jenis kendaraan mobil penumpang untuk golongan I, golongan II, dan golongan III.

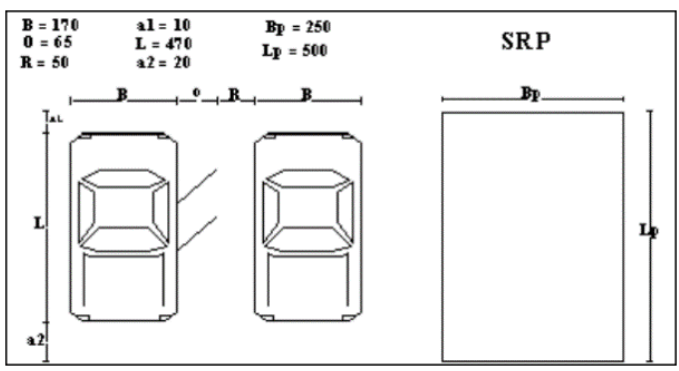

Gambar 2.Satuan Ruang Parkir (SRP) untuk Mobil Penumpang (dalam cm)

(Sumber: Pedoman Teknis Penyelenggaraan Fasilitas Parkir)

Keterangan :

B = lebar total kendaraan

$\mathrm{L} \quad=$ panjang total kendaraan 
$\mathrm{O}=$ = lebar bukaan pintu

a1, a2 = jarak bebas arah longitudinal

$\mathrm{R} \quad=$ jarak bebas arah lateral

Gol I :

$\mathrm{B}=170 \quad \mathrm{a} 1=1 \quad \mathrm{Bp}=230=\mathrm{B}+\mathrm{O}+\mathrm{R}$

$\mathrm{O}=55 \mathrm{~L}=470 \quad \mathrm{Lp}=500=\mathrm{L}+\mathrm{a} 1+\mathrm{a} 2$

$\mathrm{R}=50 \quad \mathrm{a} 2=20$

Gol II :

$\mathrm{B}=170 \quad \mathrm{a} 1=10 \quad \mathrm{Bp}=250=\mathrm{B}+\mathrm{O}+\mathrm{R}$

$\mathrm{O}=75 \quad \mathrm{~L}=470 \mathrm{Lp}=500=\mathrm{L}+\mathrm{a} 1+\mathrm{a} 2$

$\mathrm{R}=50 \quad \mathrm{a} 2=20$

Gol III :

$\mathrm{B}=170 \quad \mathrm{a} 1=10 \quad \mathrm{Bp}=300=\mathrm{B}+\mathrm{O}+\mathrm{R}$

$\mathrm{O}=80 \quad \mathrm{~L}=470 \mathrm{Lp}=500=\mathrm{L}+\mathrm{a} 1+\mathrm{a} 2$

$\mathrm{R}=50 \quad \mathrm{a} 2=20$

Berdasarkan pemaparan satuan ruang parkir untuk jenis kendaraan mobil penumpang untuk golongan I, golongan II, dan golongan III di atas, dapat diketahui bahwa luasan minimum satuan ruang parkir untuk masing-masing jenis kendaraan mobil penumpang golongan I, golongan II, dan golongan III adalah $11,5 \mathrm{~m}^{2}$, $12,5 \mathrm{~m}^{2}$, dan $15 \mathrm{~m}^{2}$.

Sedangkan berikut merupakan gambaran mengenai satuan ruang parkir untuk jenis kendaraan bus/truk.

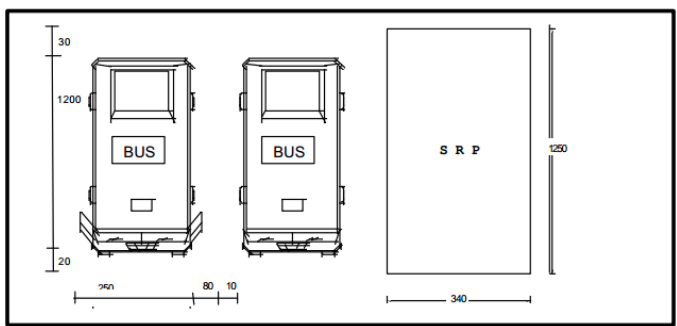

Gambar 3.Satuan Ruang Parkir (SRP) untuk Bus/ Truk (dalam cm)

(Sumber: Pedoman Teknis Penyelenggaraan Fasilitas Parkir)

Berdasarkan pemaparan satuan ruang parkir untuk jenis kendaraan bus/truk di atas, dapat diketahui bahwa luasan minimum satuan ruang parkir untuk masing-masing jenis kendaraan bus/truk adalah $42,5 \mathrm{~m}^{2}$. Kemudian, berikut merupakan gambaran mengenai satuan ruang parkir untuk jenis kendaraan sepeda motor.

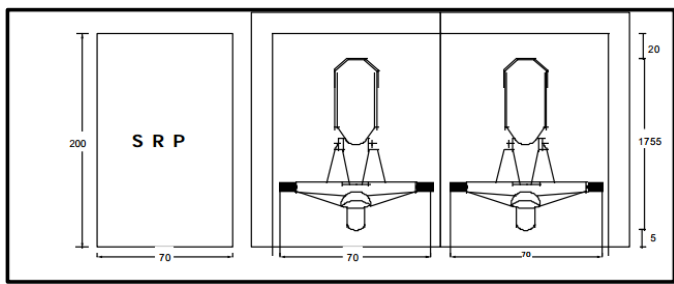

Gambar 4. Satuan Ruang Parkir (SRP) untuk Sepeda Motor (dalam $\mathrm{cm}$ )

(Sumber: Pedoman Teknis Penyelenggaraan Fasilitas Parkir)

Berdasarkan pemaparan satuan ruang parkir untuk jenis kendaraan bus/truk di atas, dapat diketahui bahwa luasan minimum satuan ruang parkir untuk masing-masing jenis kendaraan sepeda motor adalah $1,5 \mathrm{~m}^{2}$.

Kondisi eksisting parkir di Taman Wisata Alam (TWA) Kawah ljen adalah dengan menggunakan parkir menyudut $90^{\circ}$, sehingga standar ruang parkir yang digunakan untuk kendaraan seperti terlihat pada gambar dan tabel berikut.

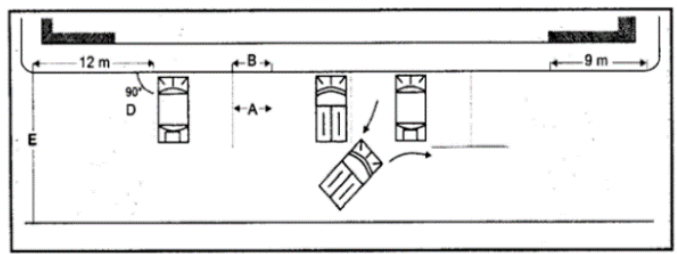

Gambar 5. Parkir Menyudut dengan Sudut $90^{\circ}$ (Sumber: Pedoman Teknis Penyelenggaraan Fasilitas Parkir)

Tabel 1.2 Ketentuan Parkir Menyudut Dengan Sudut $90^{\circ}$

\begin{tabular}{llllll}
\hline Golongan & $\mathrm{A}$ & $\mathrm{B}$ & $\mathrm{C}$ & $\mathrm{D}$ & $\mathrm{E}$ \\
\hline $\mathrm{I}$ & 2,30 & 2,30 & - & 5,40 & 11,20 \\
\hline II & 2,50 & 2,50 & - & 5,40 & 11,20 \\
\hline III & 3,00 & 3,00 & - & 5,40 & 11,20
\end{tabular}

Sumber: Pedoman Teknis Penyelenggaraan Fasilitas Parkir

Keterangan :

$A=$ Lebar ruang parkir $(m)$

$B=$ Lebar kaki ruang parkir $(m)$

$\mathrm{C}=$ Selisih panjang ruang parkir $(\mathrm{m})$

$\mathrm{D}=$ Ruang parkir efektif $(\mathrm{m})$

$M=$ Ruang manuver $(m)$

$E$ = Ruang parkir efektif ditambah ruang manuver $(\mathrm{m})$ 


\section{Metodologi}

Penelitian ini menggunakan pendekatan metode campuran. Penelitian metode campuran merupakan pendekatan penelitian yang mengkombinasikan atau mengasosiasikan bentuk kualitatif dan bentuk kuantitatif (Creswell, 2010). Pendekatan ini lebih kompleks dari sekedar mengumpulkan dan menganalisis dua jenis data; ia juga melibatkan fungsi dari dua pendekatan penelitian tersebut secara kolektif sehingga kekuatan penelitian ini secara keseluruhan lebih besar ketimbang penelitian kualitatif dan kuantitatif (Creswell \& Plano Clark, 2007). Oleh karena itu, penggunaan metode penelitian campuran ini diharapkan mampu memberikan pemahaman yang lebih baik tentang permasalahan dan pertanyaan penelitian daripada jika dilakukan secara sendiri - sendiri.

\subsection{Metode Pengumpulan Data}

Metode pengumpulan data yang digunakan dalam penelitian ini terdiri dari data primer dan data sekunder. Data primer yang dimaksud diperoleh dari penyebaran kuesioner yang telah disebarkan baik kepada wisatawan nusantara maupun wisatawan mancanegara terkait penggunaan jenis kendaraan yang digunakan untuk menuju Taman Wisata Alam (TWA) Kawah ljen. Sementara data sekunder terdiri dari data luasan parkir di Taman Wisata Alam (TWA) Kawah ljen, jumlah pengunjung Taman Wisata Alam (TWA) Kawah ljen, dan luasan kawasan Taman Wisata Alam (TWA) Kawah ljen.

\subsection{Metode Analisis Data}

Penelitian ini menggunakan pendekatan metode penelitian kuantitatif dan deskriptif kualitatif. Metode penelitian deskriptif kualitatif digunakan untuk mengidentifikasi gambaran kondisi transportasi penunjang pariwisata di Kabupaten Banyuwangi. Selain itu, metode analisis yang juga digunakan dalam penelitian ini berupa perhitungan kebutuhan penyediaan parkir berdasarkan Keputusan Direktur Jenderal Perhubungan Darat Nomor: 272/HK.105/DRJD/96 tentang Pedoman Teknis Penyelenggaraan Fasilitas Parkir. Selanjutnya, hasil perhitungan penyediaan parkir tersebut dibandingkan dengan hasil perhitungan batasan daya dukung fisik (Physical Carrying Capacity/PCC) pada Taman Wisata Alam (TWA) Kawah ljen sehingga diketahui batasan jumlah wisatawan yang dapat ditampung dengan daya dukung lingkungan di destinasi wisata tersebut.

\section{Diskusi}

\subsection{Kondisi Transportasi Penunjang Pariwisata di Kabupaten Banyuwangi}

Selain ketersediaan angkutan kota, pemerintah Kabupaten Banyuwangi juga menyediakan angkutan khusus untuk mengakomodasi kebutuhan transportasi untuk pariwisata. Selain sebagai ajang promosi dan inovasi pariwisata, pengadaan angkutan gratis bertujuan untuk mengakomodir kebutuhan wisawatan akan angkutan umum yang saat ini pelayanannya masih belum cukup menjangkau lokasi-lokasi di luar wilayah pusat kota. Hal tersebut mengakibatkan tak jarang wisatawan yang datang memiliki kesulitan untuk menjangkau lokasi-lokasi wisata yang kebanyakan berada diluar kawasan kota Banyuwangi.

Pemerintah Kabupaten Banyuwangi juga menyediakan website khusus untuk memudahkan wisatawan mengakses informasi dan melakukan pendaftaran penumpang angkutan wisata ini. Angkutan wisata gratis ini diluncurkan pada bulan Juli tahun 2017 dan memiliki 3 unit armada yaitu 1 unit bus, 1 unit ELF dan 1 unit trooper.

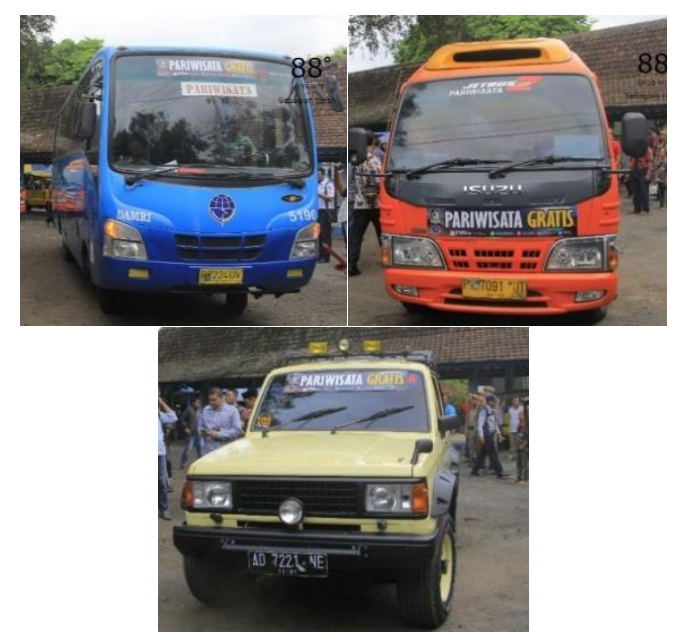

Gambar 6. Armada Wisata Gratis (Kiri Atas: Bus, Kanan Atas: ELF, Bawah : Troper) 
Masing-masing armada ini melayani rute perjalanan yang berbeda sesuai dengan kondisi aksesibilitas menuju lokasi wisata tersebut. Rute dan jadwal keberangkatannya sesuai dengan jadwal yang tertera pada website. Keberadaan angkutan wisata gratis ini cukup disambut baik oleh wisatawan yang berkunjung ke Banyuwangi. Pada 3 bulan pertama beroperasinya, angkutan ini telah mengangkut 413 penumpang dengan jumlah perjalanan sebanyak 56 kali.

\subsection{Analisis Daya Dukung Fisik}

Daya dukung fisik (Physical Carrying Capacity/PCC) merupakan jumlah maksimum wisatawan yang secara fisik tercukupi oleh ruang yang disediakan pada waktu tertentu (Cifuentes, 1992; Khair, 2008; Sustri, 2009; Sayan dan Atik, 2011). Untuk mengetahui daya dukung fisik tersebut, dilakukan perhitungan menggunakan persamaan menurut Fandeli dan Muhammad (2009) sebagai berikut.

Di mana:

$$
P C C=A \times \frac{1}{B} \times R f
$$

PCC adalah daya dukung fisik;

A adalah luas kawasan wisata sebagai blok pemanfaatan;

$B$ adalah kebutuhan ruang pengunjung untuk berwisata (menggunakan asumsi $60 \mathrm{~m}^{2}$ );

$\mathrm{R}_{\mathrm{f}}$ adalah faktor rotasi kunjungan dalam satu hari atau merupakan perbandingan antara jam buka obyek wisata dibagi dengan rata-rata lama kunjungan wisatawan.

Berdasarkan data yang diperoleh guna mengetahui nilai daya dukung fisik Taman Wisata Alam (TWA) Kawah ljen, diketahui bahwa:

- Luas area publik Kawah ljen = 7,607 hektar.

- Luas area usaha Kawah ljen $\pm 16,243$ hektar.

- Menurut Fadeli dan Muhammad dalam Purwanto (2014), kebutuhan ruang pengunjung untuk berwisata adalah seluas $60 \mathrm{~m}^{2}$.

- Rerata waktu yang dihabiskan untuk satu siklus kunjungan adalah 6 jam.

- Kawasan Kawah ljen dibuka pada malam hari pukul 23:00 -12:00 WIB (12 jam), namun untuk pariwisata Kawah ljen terdapat dua gelombang pembukaan waktu masuk wisatawan.

Berdasarkan data yang diketahui di atas, maka dapat dilakukan perhitungan daya dukung fisik
Taman Wisata Alam (TWA) Kawah ljen sebagai berikut.

$$
\begin{gathered}
P C C=(7,607+16,243) \times \frac{1}{60} \times \frac{12 \mathrm{jam}}{6 j a m} \\
P C C=238,500 \times \frac{1}{60} \times \frac{12 \mathrm{jam}}{6 j a m} \\
P C C=3,975 \times 2 \mathrm{jam}
\end{gathered}
$$

$P C C=7,950$ orang/hari

$P C C=7,950 \times 365$ orang/tahun

\section{$P C C=2,901,750$ orang/tahun}

Berdasarkan hasil perhitungan daya dukung fisik di atas, diketahui bahwa batas jumlah wisatawan yang dapat mengunjungi Taman Wisata Alam (TWA) Kawah Ijen adalah sebanyak 2,901,750 orang/tahun atau 7,950 orang/hari. Hasil perhitungan tersebut sebagai bahan untuk dibandingkan dengan perhitungan kebutuhan penyediaan parkir di Taman Wisata Alam (TWA) Kawah Ijen.

\subsection{Analisis Kebutuhan Penyediaan Parkir}

Keberadaan lahan parkir pada lokasi wisata merupakan suatu hal yang sangat penting untuk diperhatikan. Analisis perhitungan kebutuhan penyediaan parkir pada penelitian ini terdiri dari dua tahap, yaitu perhitungan kebutuhan penyediaan parkir berdasarkan proporsi penggunaan kendaraan untuk menuju Kawasan Wisata ljen (nilai proporsi diperoleh berdasarkan hasil kuesioner wisatawan) pada tahap pertama dan perhitungan kebutuhan penyediaan parkir berdasarkan proporsi target kapasitas parkir $70 \%$ untuk angkutan umum berupa ELF dan $30 \%$ untuk mobil pribadi (sebagai strategi pembatasan pengunjung ke Taman Wisata Alam (TWA) Kawah ljen).

Untuk perhitungan kebutuhan penyediaan parkir pada tahap 1, perhitungan menggunakan proporsi penggunaan kendaraan oleh wisatawan (berdasarkan hasil kuesioner terhadap wisatawan) yaitu: $31 \%$ menggunakan motor, $54 \%$ mobil, $11 \%$ dengan travel (ELF), dan trooper 4\%. Luas lahan parkir yang tersedia di Taman Wisata Alam (TWA) Kawah ljen adalah seluas $11.500 \mathrm{~m}^{2}$. Dengan menggunakan proporsi kendaraan seperti di atas, maka diasumsikan jumlah kendaraan yang datang ke Taman Wisata Alam (TWA) Kawah ljen adalah sebagai berikut: 


\section{i. Motor}

$31 \% \times 11.500 \mathrm{~m}^{2}=3.565 \mathrm{~m}^{2}$

SRP untuk motor adalah $2 \mathrm{~m}^{2}$, sehingga jumlah motor yang mampu tertampung :

$3.565 \mathrm{~m}^{2}: 2 \mathrm{~m}^{2}=1.782$ unit

Kapasitas motor 2 orang, sehingga dengan jumlah motor 1.782 unit jumlah wisatawan yang diasumsikan datang dengan menggunakan motor adalah:

1.782 unit $\times 2$ orang $=3.564$ orang

\section{ii. Mobil}

$54 \% \times 11.500 \mathrm{~m}^{2}=6.210 \mathrm{~m}^{2}$

SRP untuk motor adalah $11,5 \mathrm{~m}^{2}$ termasuk dalam jenis mobil golongan I, sehingga jumlah mobil yang mampu tertampung :

$6.210 \mathrm{~m}^{2}: 11,5 \mathrm{~m}^{2}=540$ unit

Kapasitas mobil adalah 8 orang, sehingga dengan jumlah mobil 496 unit jumlah wisatawan yang diasumsikan datang dengan menggunakan mobil adalah :

540 unit $\times 8$ orang $=4320$ orang

\section{iii. ELF}

$11 \% \times 11.500 \mathrm{~m}^{2}=1.265 \mathrm{~m}^{2}$

SRP untuk ELF adalah $16,5 \mathrm{~m}^{2}$ termasuk dalam jenis mobil golongan III, sehingga jumlah motor yang mampu tertampung :

$1.265 \mathrm{~m}^{2}: 16,5 \mathrm{~m}^{2}=77$ unit

Kapasitas ELF adalah 11 orang, sehingga dengan jumlah ELF 77 unit jumlah wisatawan yang diasumsikan datang dengan menggunakan ELF adalah :

77 unit $\times 11$ orang $=847$ orang

\section{iv. Trooper}
$4 \% \times 11.500 \mathrm{~m}^{2}=460 \mathrm{~m}^{2}$
SRP untuk trooper adalah $12,5 \mathrm{~m}^{2}$ termasuk dalam jenis mobil golongan II, sehingga jumlah trooper yang mampu tertampung :
$460 \mathrm{~m}^{2}: 12,5 \mathrm{~m}^{2}=37$ unit
Kapasitas trooper adalah 6 orang, sehingga dengan jumlah trooper 37 unit jumlah wisatawan yang diasumsikan datang dengan menggunakan trooper adalah:
37 unit $\times 6$ orang $=222$ orang

Berdasarkan hasil perhitungan dan asumsi yang digunakan, diketahui jumlah wisatawan ke Taman Wisata Alam (TWA) Kawah Ijen adalah:

$$
3.564+4320+847+222=8.953 \text { orang/hari }
$$

Berdasarkan hasil perhitungan di atas, dengan luasan lahan parkir yang tersedia di Taman Wisata Alam (TWA) Kawah ljen saat ini serta dengan menggunakan asumsi proporsi penggunaan kendaraan untuk menuju Kawasan Wisata ljen oleh wisatawan, maka dapat diketahui perkiraan potensi jumlah wisatawan yang berkunjung ke Taman Wisata Alam (TWA) Kawah ljen adalah 8.953 wisatawan per hari. Jumlah tersebut melebihi batas jumlah wisatawan yang dapat mengunjungi Taman Wisata Alam (TWA) Kawah ljen berdasarkan perhitungan daya dukung fisik Taman Wisata Alam (TWA) Kawah ljen yaitu sebanyak 7,950 orang/hari. Oleh karena itu, dilakukan perhitungan kebutuhan penyediaan parkir tahap 2 di mana perhitungan menggunakan proporsi target kapasitas parkir $70 \%$ untuk angkutan umum berupa ELF dan $30 \%$ untuk mobil pribadi (sebagai strategi pembatasan pengunjung ke Taman Wisata Alam (TWA) Kawah ljen). Berikut merupakan perhitungan perkiraan jumlah kendaraan yang mampu ditampung dengan luas lahan parkir yang tersedia $\left(11.500 \mathrm{~m}^{2}\right)$ dengan menggunakan proporsi target kapasitas parkir $70 \%$ untuk angkutan umum berupa ELF dan $30 \%$ untuk mobil pribadi.

\section{i. Angkutan umum :}

$70 \% \times 11.500 \mathrm{~m}^{2}=8.050 \mathrm{~m}^{2}$

Satuan ruang parkir untuk ELF adalah $16,5 \mathrm{~m}^{2}$ sehingga dengan luas lahan 8.050 $\mathrm{m}^{2}$ mampu menampung :

$8.050 \mathrm{~m}^{2}: 16,5 \mathrm{~m}^{2}=487$ unit ELF

Dengan kapasitas ELF sebanyak 11 orang, maka jumlah wisatawan yang diperkirakan datang adalah : 487 unit $\times 11=5.357$ orang

\section{ii. Mobil pribadi :}

$30 \% \times 11.500 \mathrm{~m}^{2}=3.450 \mathrm{~m}^{2}$

Satuan ruang parkir untuk mobil pribadi adalah $11,5 \mathrm{~m}^{2}$ sehingga dengan luas lahan $3.450 \mathrm{~m}^{2}$ mampu menampung :

$3.450 \mathrm{~m}^{2}: 11,5 \mathrm{~m}^{2}=300$ unit mobil

Dengan kapasitas mobil pribadi sebanyak 8 orang, maka jumlah wisatawan yang diperkirakan datang adalah : 300 unit $\times 8$ $=2400$ orang

Sehingga, dengan dilakukannya peraturan pembatasan kapasitas lahan parkir untuk kendaraan pribadi, maka jumlah wisatawan maksimal yang mengunjungi ljen adalah sebagai berikut: 


\subsection{7 orang +2.400 orang $=7.757$ orang/hari}

Berdasarkan hasil perhitungan di atas, maka jumlah potensi perkiraan wisatawan yang berkunjung setelah dilakukan penerapan pembatasan dan pengelolaan kapasitas lahan parkir adalah 7.795 orang per hari di mana jumlah tersebut di bawah batas jumlah wisatawan yang dapat mengunjungi Taman Wisata Alam (TWA) Kawah ljen berdasarkan perhitungan daya dukung fisik Taman Wisata Alam (TWA) Kawah ljen yaitu sebanyak 7,950 orang per hari.

\section{Kesimpulan}

Konsep pengembangan berdasarkan target konsep pariwisata berkelanjutan (sustainable tourism) dilakukan untuk merencanakan kebutuhan penyediaan parkir agar tetap dapat mendukung keberlanjutan pariwisata di Taman Wisata Alam (TWA) Kawah ljen. Untuk dapat mewujudkan batasan jumlah wisatawan ke Taman Wisata Alam (TWA) Kawah ljen sebanyak 7.950 orang/hari, salah satu upaya yang dapat dilakukan adalah dengan melakukan pengelolaan penyediaan parkir melalui pembatasan kapasitas parkir untuk kendaraan pribadi yang diharapkan dapat membatasi pengunjung ke Taman Wisata Alam (TWA) Kawah ljen. Penerapan pembatasan kapasitas parkir melalui penetapan proporsi target kapasitas parkir yaitu sebesar $70 \%$ untuk angkutan umum (berupa ELF) dan 30\% untuk mobil pribadi. Dengan luasan lahan parkir yang tersedia di pembatasan kapasitas parkir saat ini yaitu seluas $11.500 \mathrm{~m}^{2}$, maka luasan lahan parkir yang dapat disediakan untuk kendaraan pribadi adalah seluas $3.450 \mathrm{~m}^{2}$ di mana mampu menampung kurang lebih 300 unit mobil per hari, sedangkan sisanya untuk parkir angkutan umum. Dengan dilakukannya pembatasan kapasitas parkir ini, diharapkan wisatawan yang datang akan menggunakan angkutan wisata dan jumlah wisatawan maksimal yang dapat mengunjungi ljen adalah 7.757 org/hari sehingga mampu berkontribusi dalam mengurangi beban jalan dan polusi udara yang dihasilkan oleh kendaraan bermotor yang menuju dan dari Taman Wisata Alam (TWA) Kawah Ijen.

Saran untuk penelitian lanjutan adalah terkait dilaksanakannya penelitian yang lebih mendalam terkait peran pembatasan kapasitas parkir guna membatasi jumlah kunjungan wisatawan terhadap suatu kawasan wisata alam.

\section{Daftar Pustaka}

Azis, Azis, Iwan J. dkk. 2010. Pembangunan berkelanjutan; Peran dan Kontribusi Emil Salim. Cetakan 1. Jakarta: KPG (Kepustakaan Populer Gramedia) ISBN: 978-979-91-0258-4.

Cifuentes, Miquel. 1992. Determinacion de Capacidad de Carga Truistica en Areas Protegidas. Publicacion Patrocinada Por el Fondo Mundial para la Naturaleza-WWF. Serie Tecnica Informe Tecnico No. 194. Centro Agronomico Tropical de Investigacion $Y$ Ensenanza CATIE, Programa de Manejo Integrado de Recursos Naturales. Turrialba, Costa Rica.

Creswell, John W., Vicki L. Plano Clark. 2007. Designing and Conducting Mixed Methods Research. Thousand Oaks: SAGE Publications.

Creswell, J.W. 2010. Research design: pendekatan kualitatif, kuantitatif, dan mixed. Yogyakarta: PT Pustaka Pelajar.

Fandeli C, Muhammad. 2009. Prinsip-Prinsip Dasar Mengkonservasi Lanskap. Yogyakarta: Gadjah Mada University Press.

Keputusan Direktur Jenderal Perhubungan Darat Nomor: 272/HK.105/DRJD/96 tentang Pedoman Teknis Penyelenggaraan Fasilitas Parkir.

Khair, Uzunu. 2006. Kapasitas Daya Dukung Fisik Kawasan Ekowisata Di Taman Wisata Alam (TWA) Sibolangit Kabupaten Deli Serdang. Tesis. Medan: Sekolah Pasca Sarjana Universitas Sumatera Utara.

Lisnawati. 2014. Penyusunan Standar Parkir Pusat Perbelanjaan di Kota Bandung. Tugas Akhir. Bandung: Program Studi Perencanaan Wilayah dan Kota ITB.

Livina, Agita (Editor). 2009. Sustainable Planning Instruments and Biodiversity Conservation. Vidzeme University of Applied Science, Latvia.

Magister PWK ITB. 2018. Laporan Fakta dan Analisis Studio Perencanaan Sistem Infrastruktur dan Transportasi Kabupaten Banyuwangi.

McCool, Stephen and Moisey, R. Neil (editor). 2008. Tourism, recreation, and sustainability: linking culture and the 
environment 2nd edition. $\mathrm{CAB}$ International. Oxfordshire, United Kingdom.

Permana, Sidik. 2016. Antropologi Perdesaan dan Pembangunan Berkelanjutan. Ed. 1 Cet. 1. Yogyakarta: Deepublish ISBN 978-602-401-594-7.

Purwanto, Sigit. 2014. Kajian Potensi dan Daya Dukung Taman Wisata Alam Bukit Kelam Untuk Strategi Pengembangan Ekowisata. Tesis. Bogor: Sekolah Pascasarjana Institut Pertanian Bogor.

Sayan, Mustafa Selcuk dan Atik, Meryem. 2011. Recreation Carrying Capacity Estimates for Protected Areas: A Study of Termessos National Park (Turkey). Ekoloji 20 (78): 66-74.

Soemarwoto, Otto. 2004. Ekologi, Lingkungan Hidup dan Pembangunan Edisi ke-10. Jakarta: Penerbit Djambatan.

Steck, Birgit. 1999. Sustainable Tourism as a Development Option: Practical Guide for Local Planners, Developers and Decision Makers. Federal Ministry for Economic Co-operation and Development and Deutsche Gesellschaft für Technische Zusammenarbeit (GTZ) GmbH. Bonn, Jerman.

Suryadana, Liga. 2013. Sosiologi Pariwisata: Kajian Kepariwisataan dalam Paradigma Integratif-Transformatif menuju Wisata Spiritual. Bandung: Humaniora.

Sustri. 2009. Daya Dukung Wisata Alam di Taman Nasional Kepulauan Togean Sulawesi Tengah. Tesis. Pasca Sarjana IImu Kehutanan Universitas Gadjah Mada. Yogyakarta.

Tim Kementrian Pariwisata. 2017. Buku Pedoman Pemberian Penghargaan bagi Destinasi Pariwisata Berkelanjutan. Jakarta: Kemenpar.

WTO. 2004. Indicators of Sustainabel Development for Tourism Destinations A Guide Book. World Tourism Organization. Madrid, Spain.

Young, William. 2001. Parking and Traffic Control dalam Handbook of Transport Modelling Volume 3. Kidlington: Elsevier Science Ltd. 